\section{Invasive myocardial calcification of left ventricle associated with conduction disturbances, hypophosphatemia, and childhood rickets}

A 20-year-old female patient was admitted for mitral stenosis and regurgitation. Her past medical history was unremarkable, except for a childhood diagnosis of rickets. She had slight hypophosphatemia in the preoperative workup. Her electrocardiography revealed first-degree and left bundle branch blocks and intraventricular conduction delay (Fig. 1). There was no systolic dysfunction on echocardiography, but the pulmonary artery systolic pressure was $110 \mathrm{~mm} \mathrm{Hg}$. Myocardial calcifications were apparent on the chest x-ray (Fig. 2a). Computed tomography revealed the infiltrative nature of the calcinosis, involving predominantly the left ventricular myocardium (Fig. 2b-2d, Videos 1-4). However, the pericardium and coronary arteries were somehow spared, and no other organ involvement was detected. During the operation, spike-shaped protrusions because of subendocardial/myocardial calcium deposits were noticeable, resembling the stalactite/stalagmite formations in a cave. The patient underwent a successful mitral valve replacement using a mechanical prosthesis.

Myocardial calcification is usually classified as either metastatic or dystrophic, the latter being more common (1). Idiopathic cardiac calcification, calcifications in the elderly, and calcifications secondary to endomyocardial fibrosis, chronic kidney disease, or trauma have also been reported (2). In this patient, metastatic calcification was ruled out owing to the absence of other organ calcification, and degenerative or atherosclerotic processes were not relevant as the patient was young. Thus, the underlying cause remains obscure.

Possible clinical implications of myocardial calcinosis in this patient may include severe pulmonary hypertension owing to

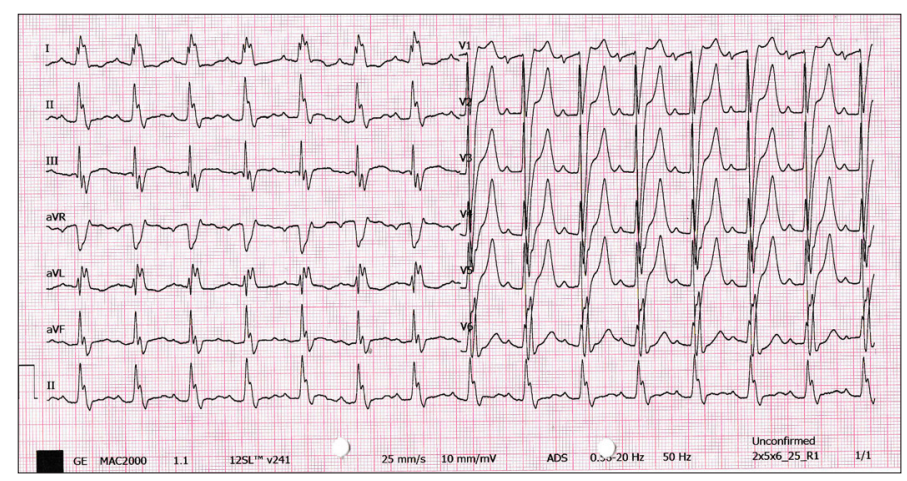

Figure 1. Preoperative electrocardiography revealing combined first-degree and left bundle branch blocks and intraventricular conduction delay

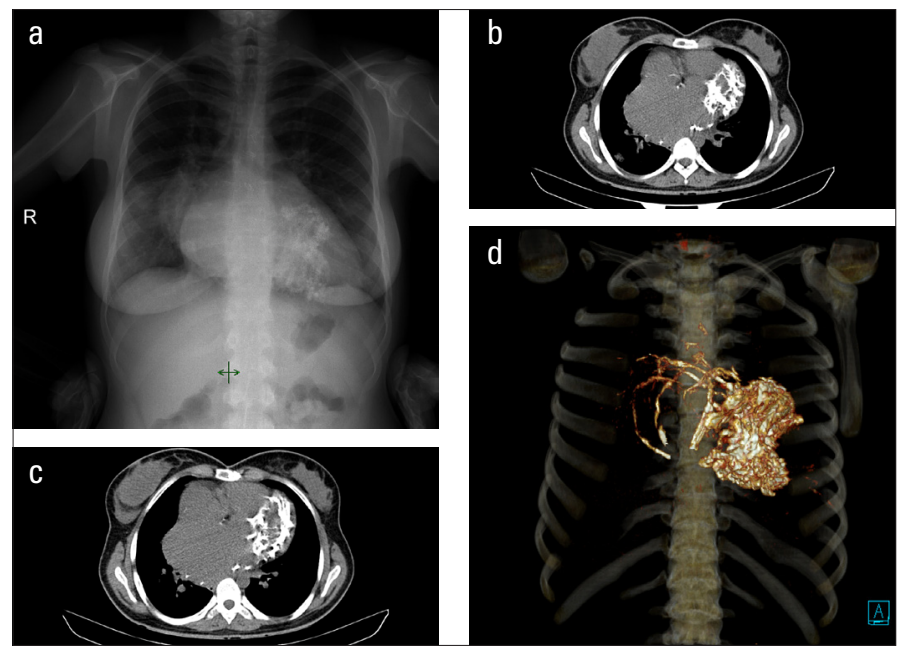

Figure 2. a) Chest $x$-ray depicting heavy calcification on the cardiac silhouette. b) Involvement of the left ventricle (computed tomography without contrast). c) Isolated infiltrative calcification of the myocardium on computed tomography (without contrast). The pericardium and coronary arteries were spared. No other organ involvement was detected. d) Three-dimensional computed tomography image retrieved with volume rendering technique

restrictive physiology and conduction disturbances. As progressive calcific invasion of the conduction pathways may lead to complete heart block (3), close follow-up of the patient is imperative.

Informed consent: A written informed consent was obtained from the patient.

Video 1. Multiplanar reformation computed tomography - sagittal plane (without contrast)

Video 2. Multiplanar reformation computed tomography - short-axis plane (without contrast)

Video 3. Multiplanar reformation computed tomography - transverse plane (without contrast)

Video 4. Three-dimensional color computed tomography footage retrieved with volume rendering technique

\section{References}

1. Gowda RM, Boxt LM. Calcifications of the heart. Radiol Clin North Am 2004; 42: 603-17, vi-vii. [Crossref]

2. Nance JW Jr, Crane GM, Halushka MK, Fishman EK, Zimmerman SL. Myocardial calcifications: pathophysiology, etiologies, differential diagnoses, and imaging findings. J Cardiovasc Comput Tomogr 2015; 9: 58-67. [Crossref]

3. Isotalo PA, Halil A, Green M, Tang A, Lach B, Veinot JP. Metastatic calcification of the cardiac conduction system with heart block: an under-reported entity in chronic renal failure patients. J Forensic Sci 2000; 45: 1335-8. [Crossref] 
Kerem M. Vural (D), Burak Ateşsaçan (D), Can Kerestecioğlu (D), Furkan Gül (iD)

Department of Cardiovascular Surgery, Faculty of Medicine, Hacettepe University; Ankara-Turkey
Address for Correspondence: Dr. Kerem M. Vural,

Hacettepe Üniversitesi Tıp Fakültesi, Kalp ve Damar Cerrahisi Anabilim Dalı,

Ankara-Türkiye

Phone: +90 3123051773

E-mail: keremvural@hacettepe.edu.tr

(C) Copyright 2021 by Turkish Society of Cardiology -

Available online at

www.anatoljcardiol.com

DOI:10.5152/AnatolJCardiol.2021.00748 